\title{
Trauma deaths in children: a preliminary report
}

\section{Babatunde A. Solagberu}

Department of Surgery, University of Ilorin Teaching Hospital, Ilorin, Nigeria. Reprint requests to: Dr. B. A. Solagberu, P. O. Box 4377, Ilorin, Nigeria.

E-mail: basolagberu@yahoo.com

$*$ Paper presented at the $40^{\text {th }}$ Scientific Conference of the Nigerian Surgical Research Society, Ilorin, Nigeria. $30^{\text {th }}$ November to $2^{\text {nd }}$ December 2000.

\begin{abstract}
Background/Objectives: Childhood trauma data, in developing countries, requires updating to highlight problems in childhood trauma care. This study was done to examine childhood trauma deaths in the Accident and Emergency room ( $\mathrm{A}$ and $\mathrm{E})$.

Methods: A prospective trauma analysis of children aged 15 years and below attending the surgical A and E was done from September 1999 to August 2000. Data collected included age (0-4 years, >4-9 years, >915 years), sex, causes of trauma, injury-arrival time, the quality and outcome of care and the circumstances of death.

Results: Out of 543 children seen, 327 were boys and 216 were girls. Most of the children were in the age group $>9-15$ years $(215,39.6 \%)$. Trauma occurred in 391 children $(72.0 \%)$ due to road traffic accidents (RTA, 169 children, $31.1 \%$ ), falls $(75,13.8 \%$ ), burns and scalds $(37,6.8 \%)$, other domestic accidents $(35,6.5 \%)$, foreign body $(\mathrm{FB})$ in the orifices $(37,6.8 \%)$, assaults $(20,3.7 \%)$, occupational injuries $(10$, $1.8 \%)$ and gunshot injuries $(8,1.5 \%)$. There were seven deaths (mortality $1.3 \%$ ); three each from burns ( $38 \%-60 \%$ burns, 2 of whom reported 1-2 weeks after burns) and pedestrian RTA (all with head injury, 2 of whom had other injuries) while one child had airway obstruction from a FB. All the deaths were on day 1 of admission.

Conclusion: Trauma is the commonest surgical problem seen in childhood in the $\mathrm{A}$ and $\mathrm{E}$ and largely preventable. Children have good outcome from trauma with low mortality, but this can be further decreased. Evidence from the preventable nature of the deaths presents strong arguments in favour of better organization of trauma care and reinforcing public health education especially concerning care of children of working parents.
\end{abstract}

\section{Key words: Trauma deaths, children}

\section{Introduction}

Trauma death studies are important for medical audit on the quality of care provided to the public and for analysing how and where the trauma system failed. ${ }^{1}$ Adeloye and Odeku $^{2}$ in $1970 \mathrm{had}$ predicted that trauma would assume greater public health significance in years to come. Hendrickse 
Solagberu B. A. Childhood trauma deaths in Nigeria.

in 1967 , according to Ebong, ${ }^{3}$ reported infections and nutritional diseases as the major causes of morbidity and mortality in childhood in developing countries. However, the burden of these probably relegated trauma to the background. At present, accidents have been displacing infectious diseases as a major cause of death in children in the developed countries. ${ }^{4}$ With the burden of infections now getting some control in developing countries, trauma has become the most common surgical disease in African children. ${ }^{5-7}$

This study was done to examine deaths from trauma in children presenting to the Accident and Emergency (A and $E$ ) of the University of Ilorin Teaching Hospital, llorin, Nigeria. Indeed, hospital records of patients are useful indices in describing disease prevalence, $9,10,11$ results of this study will contribute to trauma data from developing countries.

\section{Patients and Methods}

A prospective study of children 15 years and below attending the surgical $A$ and $E$ of the University of Ilorin Teaching Hospital, Ilorin,
Nigeria was done from September 1999 to August 2000. This report reflects the trauma deaths from that study. Details about age (0-4 years, $>4-9$ years, >9-15 years), sex, causes of trauma, injuryarrival time, the quality and outcome of care and the circumstances of death were analysed.

\section{Results}

Out of 543 children aged 15 years and below, 327 were boys while 216 were girls $(\mathrm{M}: \mathrm{F}=1.5: 1)$, Table 1. There were 174 children $(32.0 \%)$ in the preschool age group $0-4$ years, $154(28.4 \%)$ were of school age $>4-9$ years, while children $>9-15$ years of early adolescence period were 215 (39.6 $\%)$. Trauma occurred in 391 children $(72.0 \%)$. Road traffic accidents, RTA, accounted for the majority of the traưma with 169 patients, $31.1 \%$. Nearly two thirds of the RTA patients were pedestrians $(109$ of $169,64.5 \%)$. Other forms of trauma were falls ( 75 patients, $13.8 \%$ ), burns and scalds (37 patients, $6.8 \%)$, other domestic accidents $(35,6.5 \%)$, foreign body in the orifices $(37,6.8 \%)$, assaults $(20,3.7 \%)$, occupational accidents $(10,1.8 \%)$ and gunshot injuries $(8,1.5$ $\%$ ).

Table 1: Age and sex of 543 children.

\begin{tabular}{llll}
\hline Age (yrs) & Male & Female & Total $(\%)$ \\
\hline $0-4$ & $108(19.9 \%)$ & $66(12.2 \%)$ & $174(32.0 \%)$ \\
$>4-9$ & $90(16.6 \%)$ & $64(11.8 \%)$ & $154(28.4 \%)$ \\
$>9-15$ & $129(23.7 \%)$ & $86(15.8 \%)$ & $215(39.6 \%)$ \\
\hline Total $(\%)$ & $327(60.2 \%)$ & $216(39.8 \%)$ & $543(100.0 \%)$ \\
\hline
\end{tabular}

Table 2: Children with Burns, Head Injury, Foreign Body (3 conditions associated with mortality)

\begin{tabular}{|c|c|c|c|c|c|c|}
\hline \multirow[t]{3}{*}{ Age (yrs) } & \multicolumn{4}{|c|}{ Type of trauma } & & \\
\hline & \multicolumn{2}{|c|}{ Burns } & \multicolumn{2}{|c|}{ Head injury } & \multicolumn{2}{|c|}{ Foreign body } \\
\hline & $\mathrm{M}$ & $\mathrm{F}$ & $\mathrm{M}$ & $\mathrm{F}$ & $\mathrm{M}$ & $\mathrm{F}$ \\
\hline $0-4$ & 12 & 11 & 11 & 3 & 12 & 7 \\
\hline$>4-9$ & 3 & 5 & 9 & 11 & 7 & 4 \\
\hline$>9-15$ & 1 & 5 & 10 & 4 & 2 & 5 \\
\hline Total & 16 & 21 & 30 & 18 & 21 & 16 \\
\hline
\end{tabular}


Table 3:Pproblems contributory to poor care and death

\section{Hypothermia}

Lack of materials in the emergency room

Lack of oxygen

Poor logistics in getting senior doctors

Electric power failure

Poor finance

Late presentation

The types of injuries sustained included superficial trauma (lacerations, abrasions and bruises: 123 children, $22.7 \%)$, fractures $(85,15.7$ $\%$ ), head injury $(48,8.8 \%$ ) with the highest incidence among the school age, Table 2 . There was male preponderance in head injury seen in the preschool and early adolescence periods unlike nearly equal sex distribution among boys and girls in the school age period, Table 2. Other injuries were burns and scalds ( 37 patients, $6.8 \%$ ) with 23 of them $(62.2 \%)$ in the $0-4$ years preschool age group, multiple injuries $(25,4.6 \%)$, foreign body swallowing or aspiration (37 patients, $6.8 \%$ ) which predominantly was a preschool age problem among 19 of these $37(51.4 \%)$ and other minor injuries $(36,6.6 \%)$. Majority of the patients (498 patients, $92.1 \%$ ) presented within 24 hours of their trauma. The admission rate was $47.9 \%(260)$ patients.

There were seven deaths ( 7 of 543 children, $1.3 \%$ ). Three deaths were recorded from burns, all in the preschool age, two boys and a girl. The extent of burns was $60 \%$ superficial burns, $38 \%$ and $40 \%$. The latter two had an injury-arrival time of 1 week and 2 weeks, respectively, while the former arrived after 30 minutes of burns. All the three died within 7-19 hours, from hypovolaemic shock in the $60 \%$ burns and sepsis and electrolyte imbalance for the other 2. Another three deaths were due to pedestrian RTA, 1 each from the preschool, school age and early adolescent age groups. Head injury was common to all the three, occurring alone as cerebral contusion in 1 child and as part of multiple injuries in the other 2-head injury and long bone fracture in one and head injury, long bone fracture and penetrating abdominal injury with gut evisceration in the other. The quality of care, Table 3, was inadequate for these severe injuries due to poor logistics support in calling for senior assistance by the junior residents, electricity power failure to work equipments, lack of essential materials like oxygen, dressing materials to prevent further heat loss from burns, and poor finance to procure needed materials and drugs.

\section{Discussion}

Interestingly, the seven deaths in this report are all trauma related: burns, head injury and foreign body in orifices. With a reported morbidity of $72.0 \%$, therefore, both in morbidity and in mortality, trauma is an important surgical disease in children. Bickler and Rode ${ }^{5}$ alerted us to this reality in stressing priorities for paediatric surgical care in Africa. Omo-dare and Akande ${ }^{10}$ in 1969 in a study of burns among 68 Nigerian children over a five-year period had reported 50 of 66 children $(75.8 \%)$ whose ages were known as belonging to the 0-4 years preschool age. Our finding agrees with this and other reports" as that age group constituted the highest incidence of burns, Table 2. The higher number of girls than boys in the older-child-burns is probably attributable to the fact that more girls help parents in the kitchen, as the burns were domestic accidents. However, the idea of the preschool child being adventurous and lacking any sense of danger as suggested by OmoDare and Akande ${ }^{10}$ means that children needed to be protected from burns by caring adults (parents and guardians). This fact is too well known but ignored. Parents often relegate this onerous task to older children employed as "house-helps", who lack education, are inexperienced, and obviously too young for the duty. Sometimes, the grandparents who are ill equipped for these energetic, adventurous children are the caregivers as in all cases of this nature; the parents have gone to work. The burn mortality of $8.1 \%$ (3 of 37 children), is slightly higher than the $6.0 \%$ by Omo-dare and Akande. ${ }^{10}$

One characteristic of childhood trauma from RTA is the high incidence of head injury occurring either alone or in association with other injuries. ${ }^{12}$ These injuries are often mild and have 
good outcome, but sometimes are severe and would require good airway and resuscitative care before transferring to the neurosurgical service. ${ }^{2}$ The morbidity of children with head injury of 8.8 $\%$ (48 of 543 patients) is similar to the $8.5 \%$ obtained from lle-Ife, Nigeria ${ }^{13}$ but slightly greater than $5.7 \%$ in Ibadan. Nigeria ${ }^{12}$. However, the mortality from childhood head injury in this series is slightly smaller ( 3 of 48 head injured children, $6.3 \%$ ) than the 10 of $104,9.6 \%$ in the Ile-Ife, Nigeria ${ }^{13}$ and the 20 of $160,12.5 \%$ from the Ibadan, Nigeria ${ }^{12}$ series. The literature is full of documented evidence of the pedestrian nature of the child RTA victim. $2,3,8,14.15,16$ Various pedestrian accident rates have been quoted, always with children constituting the majority, ranging from $51.7 \%^{3}, 57.0 \%{ }^{8}, 62.0 \%^{2}$ to 90.0 $\%{ }^{13}$. Our pedestrian rate of $64.5 \%, 109$ of 169 child RTA victims, is in keeping with recorded available literature. The children have not learnt enough road behaviour at the time of exposure to automobiles, such that they cross the road because others had crossed and especially if they were walking in a group. Children are knocked down while rushing to school oblivious of traffic, while pushing a wheelbarrow by the roadside, rolling a bicycle wheel or playing football near a highway. These situations bring the children close to the road and the vehicles that ply them. Trauma resulting from these means is preventable through urgent public health measures to separate vehicle and child through creation of sidewalks, overhead bridges or tunnels, or reducing vehicle speeds using speed-breakers in crowded parts of a city, Zebra crossings and improved road designs. That some of these efforts have been recommended in the past and still remain unobserved ${ }^{2,16}$ suggests need for their reiteration and strengthening of campaigns against RTA.

Childhood trauma from home accidents generally is another major cause for concern. Home accidents are seen commonest among the preschool age group with falls and swallowed substances highly prevalent. ${ }^{17}$ This study apart from creating a great concern for head injury, burns and foreign bodies as the most prevalent trauma disease among children also shows that the pre-school age group demands greater care for these diseases because the highest incidences of them are found in the group due to children's propensity for adventure without adequate parental supervision.

\section{Conclusion}

All the seven childhood deaths in this report were potentially preventable either from occurring or by significantly improving the first aid administered to trauma victims or by early reporting of trauma to the $A$ and $E$ especially burns and foreign bodies. The care of children by "house-helps" should be reversed and replaced with trained personnel in lieu of parents and adult guardians. Employers of labour should consider establishing crèches for working mothers where their children will be well cared for when mothers are at work, while schools should keep the children safe away from the road. Greater public enlightenment on hazards of the road for pedestrians should discourage adults from sending children on road errands or using them as child labour hawking on the streets. Traffic rules should be enforced; road designs should aim at separating vehicles and pedestrians. Expectedly, the problem of underdevelopment even affected the chance of survival in the $\mathrm{A}$ and $\mathrm{E}$, hence, efforts towards improving the socio-economic condition of the developing countries should impact on health care. Materials for resuscitation in the $\mathrm{A}$ and $\mathrm{E}$ should constantly be replenished just as there is need to improve on the logistics of junior casualty officers reaching out early and effectively to senior doctors for help. Further studies on these are continuing.

\section{Acknowledgement}

I thank the consultant surgeons whose patients formed part of this report for their co-operation.

\section{References}

1. Stocchetti N, Pagliarini G, Gennari $M$ et al. Trauma care in Italy: evidence of in-hospital preventable deaths. J Trauma 1994; 36: 401405. 
2. Adeloye A, Odeku E L. The pattern of road traffic accidents seen at the University College Hospital, Ibadan, Nigeria--a preliminary study. West Afr Med J 1970; October 153-157.

3. Ebong WW. Pattern of injuries from road traffic accidents among children. Nigerian J Paediatr 1980; 7: 20-25.

4. Gissane W, Bull J. Injuries from accidents. Practitioner 1962; 188: 489-497.

5. Bickler SW, Rode H. Priorities for paediatric surgery in Africa. Africa Health 2000; 22: 5 6, 8-9.

6. Nordberg E. Injuries in Africa: a review. East Afr Med J 1994; 71: 339-345.

7. Solagberu BA, Duze $\mathrm{T}$, Adekanye $\mathrm{AO}$, Ofoegbu CPK, Odelowo EOO. Surgical morbidity and mortality in the accident and emergency room-a preliminary report. Afr J Med Med Sci 2000; 29: 315-319.

8. Oyemade A. Epidemiology of road traffic accidents in Ibadan and its environs. Nigerian Med J 1973; 3: 174-177.

9. Hunpong-Wusu OO. Disorders, which shorten life among Nigerians. Trop Geo Med 1976; 28: 343-348.
10. Omo-Dare P, Akande BA. A study of burns in 68 children admitted into the Lagos University Teaching Hospital, 1964-1968. West Afr Med J 1969; December: 201-204.

11. Asindi AA, Efem SEE, Onuba O, Asuquo ME. Accidental trauma in children. Nigerian J Paediatr 1986; 13: 77-81.

12. Shokunbi MT, Solagberu BA. Mortality in childhood head injury in Ibadan. Afr J Med Med Sci 1995; 24: 159-163.

13. Adesunkanmi AR, Oginni LM, Oyelami OS, Badrus OS. Epidemiology of childhood injury. J Trauma 1998; 44: 506-512.

14. Perry JF, McClellan J. Autopsy findings in 127 patients following fatal traffic accidents. Surg Gynecol Obstet 1964; 119: 586-590.

15. Ebong WW. The pattern of fractures and dislocations in western Nigeria. Injury 1978; 9: 221-224.

16. Asogwa SE, Obionu CN. Urban pedestrian accidents and the efficacy of a countermeasure. Centr Afr J Med 1985; 31: 62-65.

17. Murdock R, Eva J. Home accidents to children under 15 Years: survey of 910 cases. Br Med J 1974; 3: 103-106. 